Check for updates

Cite this: Chem. Sci., 2019, 10, 2179

๑ All publication charges for this article have been paid for by the Royal Society of Chemistry

Received 28th November 2018 Accepted 15th December 2018

DOI: $10.1039 / c 8 s c 05293 j$

rsc.li/chemical-science

\section{Iron sulfur clusters in protein nanocages for photocatalytic hydrogen generation in acidic aqueous solutions $\uparrow$}

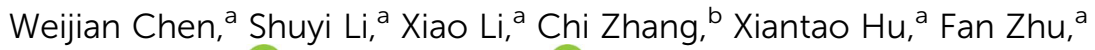 \\ Guosong Shen (D) a and Fude Feng (D) *a
}

\begin{abstract}
We took advantage of the iron binding affinity of apoferritin to immobilize iron-sulfur clusters into apoferritin up to 312 moieties per protein, with a loading rate as high as $25 \mathrm{wt} \%$. The photocatalytic hydrogen generation activity in acidic aqueous solutions was achieved with TONs up to 31 (based on a single catalyst moiety) or $8.3 \times 10^{3}$ (based on a single protein) upon $3 \mathrm{~h}$ of visible light irradiation. The present study provides a versatile strategy to construct uniform protein/photocatalyst supramolecular systems with FeFe- $\mathrm{H}_{2}$ ase activity.
\end{abstract}

Among some of the natural FeFe-hydrogenases (FeFe- $\mathrm{H}_{2}$ ase), iron sulfur clusters containing Fe-bonding $\mathrm{CO}$ ligands play a key role in photocatalytic water splitting, with an activity to produce up to 6000-9000 molecules of $\mathrm{H}_{2}$ per second. ${ }^{1,2}$ Recently, increasing research studies have been focused on developing artificial hydrogenases, particularly based on $\mathrm{Ni}$, Fe and $\mathrm{Co}$ metal complexes, for light driven water splitting purposes. ${ }^{3-5}$ Development of diiron dithiolate model complexes with water solubility becomes an important objective.

Self-assembly based biomimetic hydrogenase models are attractive due to their outstanding merits in uniformity, stability and efficacy. ${ }^{6,7}$ Generally, the active centers are located inside macromolecules or scaffolds. We briefly overviewed reported systems in Table S1 $\uparrow$ focused on the use of peptides/ proteins, ${ }^{8}$ micelles, ${ }^{9}$ nanodots, ${ }^{10}$ metal-organic-frameworks (MOFs), ${ }^{11}$ etc. Bioinspired hydrogenase mimics, especially protein-based systems immobilizing Fe-S clusters, provide unique microenvironments for synthetic catalysts. ${ }^{12}$ For example, Hayashi and coworkers reported a hydrogenase model system with an iron carbonyl cluster, $\mathrm{Fe}_{2}(\mathrm{CO})_{9}$, coordinated to apocytochrome $c$ for photochemical $\mathrm{H}_{2}$ evolution in aqueous solution..$^{13}$ The single active center in this system was stabilized by covalently linking $\mathrm{Fe}-\mathrm{S}$ clusters to cysteine residues at an accurate site, affording a turnover number (TON) up to 82 . Alternatively, hierarchical protein scaffolds immobilizing

${ }^{a}$ Key Laboratory of High Performance Polymer Material and Technology of Ministry of Education, Department of Polymer Science \& Engineering, School of Chemistry \& Chemical Engineering, Nanjing University, Nanjing 210023, China. E-mail: fengfd@ nju.edu.cn

${ }^{b}$ School of Chemistry \& Chemical Engineering, Shangqiu Normal University, Shangqiu 476000, China

$\dagger$ Electronic supplementary information (ESI) available. See DOI: $10.1039 / \mathrm{c} 8 \mathrm{sc} 05293 \mathrm{j}$ multiple active sites have multiplied complexity in structure and mechanism, showing an advantage in photocatalytic $\mathrm{H}_{2}$ generation at a reduced cost of proteins while maintaining a high TON. ${ }^{14}$

Recent approaches have revealed that micelles can act as a microreactor and provide a high concentration of catalysts and photosensitizers to result in enhanced $\mathrm{H}_{2}$ production..$^{15}$ It seems that crowded catalysts are able to maintain sufficient activity, but the mechanism behind this remains to be interpreted. Proteins can provide ideal scaffolds binding Fe-S clusters via specific interactions. Generally, natural Fe-S binding proteins such as cytochrome $c$ and nitrobindin ( $\beta$-barrel protein) bind $\mathrm{Fe}-\mathrm{S}$ clusters via covalent interaction, however, lacking sufficient binding sites. ${ }^{12,13}$ We previously reported that horse spleen apoferritin (apo-HSF) has strong binding affinity toward iron-sulfur-nitrosyl cluster anions, with a high loading capacity up to 53 Roussin's black salt moieties per single protein. ${ }^{16}$ We speculate that the negative inner surface of apoHSF plays a key role in iron binding due to the presence of abundant anionic amino acid residues in L-chains. ${ }^{17-19} \mathrm{In}$ fact, diverse metal ions, metal complexes and organic compounds could be immobilized on the interior surface of apo-HSF. ${ }^{20,21}$ Turano et al. described a structural study on the Glu60, Glu61, and Glu64 residues from horse $\mathrm{L}$-ferritins and found that these anionic residues could cooperatively bind iron in a trinuclear center which plays an important role in the biomineralization process. ${ }^{22}$ More recently, two identified Pt binding sites in the inner surface of apo-HSF were located in close proximity to His132 and His49 as revealed by an X-ray diffraction study, which might be the reason why a large amount of carboplatin could be accommodated inside the cage not just by coordination interaction. ${ }^{23}$ Similarly, Takafumi et al. reported that ferritin cages could serve as bioinorganic molecular templates 
to bind metal carbonyl compounds composed of $\mathrm{Ru}-\mathrm{CO}$ or $\mathrm{Mn}-$ CO moieties for photoactivatable $\mathrm{CO}$ release, which was confirmed by the X-ray diffraction analysis of the crystal structures. $^{\mathbf{2 4 , 2 5}}$ Considering the abundant metal binding sites and hydrophobic microenvironment in the cavity, ${ }^{26}$ we expect that apo-HSF would be an ideal nano-platform for immobilizing $\left[\mathrm{Fe}_{2}\left\{\left(\mu-\mathrm{SC}_{2} \mathrm{H}_{4}\right)(\mu-\mathrm{SCH})\left(\mathrm{CH}_{2}\right)_{4} \mathrm{COOH}\right\}(\mathrm{CO})_{6}\right](\mathrm{FeFe}-\mathrm{COOH})$ in the cages (Fig. 1 and $\mathrm{S} 1 \dagger$ ).

As a 24-mer natural protein, ferritin has a bundle of unique features, including self-assembly properties, precise cage alignment, a spacious cavity with metal binding sites, and a rigid and uniform nanostructure, which make ferritin cages widely used in biomedical applications such as drug delivery, optical imaging, cancer diagnosis and therapy, vaccine development, and artificial metalloenzymes. ${ }^{27-30}$ Due to the capability of accumulating metal complexes, ferritin cages are excellent candidates as catalyst vessels, without the need for additional organic ligands that require chemical modifications. ${ }^{31}$ Particularly, the strong diiron binding property of inner cage avoids scale-restricted biogenetic modification and minimizes the possibility of undesired catalyst leakage through the narrow pores of the cage shell in the course of the catalytic reaction. Compared to ferritin cages, other known protein cages or enzymes are dwarfed in iron accumulation. Moreover, the ferritin cages possess additional merits, such as robust structural stability, excellent water solubility and good durability. Hence, we chose ferritin cages as a carrier of diiron dithiolatetype photocatalysts and studied the hydrogenase activity of the assembled supramolecular structure in aqueous solutions.

The molecule FeFe-COOH (Fig. 1) was easily obtained by coupling the Fe-carbonyl compound and lipoic acid which is known as a cheap and natural anti-oxidant. ${ }^{32,33} \mathrm{FeFe}-\mathrm{COOH}$ was used as a catalyst and incorporated into apo-HSF at different feed ratios to form NPs. A pH alteration method that includes protein unfolding at $\mathrm{pH} 2$ and refolding to the original structure

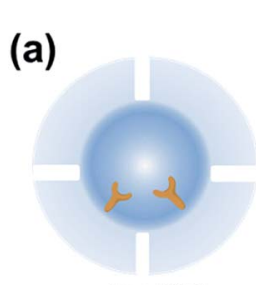

Apo-HSF

(b)

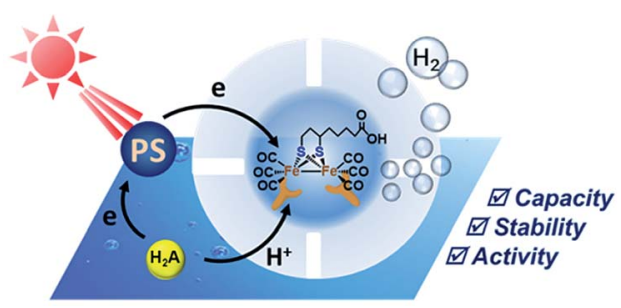

Fig. 1 (a) Schematic illustration of artificial hydrogenase construction by encaging multiple $\mathrm{Fe}-\mathrm{S}$ cluster-based catalysts into the apoferritin cavity. (b) Schematic representation of photocatalytic $\mathrm{H}_{2}$ evolution by FeFe nanoparticles (NPs) in aqueous media. PS and $\mathrm{H}_{2} \mathrm{~A}$ denote the photosensitizer $\mathrm{Ru}(\mathrm{bpy})_{3}{ }^{2+}$ and ascorbic acid, respectively. at neutral or basic $\mathrm{pH}$ in the presence of a guest molecule for loading was widely applied. ${ }^{34}$ However, the loading of FeFe$\mathrm{COOH}$ could be achieved at a constant $\mathrm{pH}$ of 7.4 without involving a protein disassembly process, similar to the previous example preparing Roussin's black salt@apo-HSF nanocomposites. ${ }^{16}$ The NPs were purified by successive dialysis against $10 \%$ acetonitrile-PBS (pH 7.4) and PBS, and finally on PD 10 desalting columns. According to the spectrophotometric analysis, the NPs contained 61 to $624 \mathrm{Fe}$ atoms (equivalent to 30 to $312 \mathrm{FeFe}-\mathrm{COOH}$ moieties per single protein) with a loading efficiency (LE) up to $10 \%$ (Table 1), dependent on the feed ratios.

The resultant NPs, with NP4 prepared at a fixed molar feed ratio of $2000: 1$ as an example, exhibited two intense broad absorption bands in the UV-vis spectra at 300-400 $\mathrm{nm}$ and 450$600 \mathrm{~nm}$ originating from $\mathrm{FeFe}-\mathrm{COOH}$ (Fig. S2 $\dagger$ ), and $\mathrm{CO}-$ stretching bands in the Fourier transform infrared (FT-IR) spectra that were identical to those of the unbound catalyst complexes in the $1950-2100 \mathrm{~cm}^{-1}$ range (Fig. 2a), thus

Table 1 Composition of NPs

\begin{tabular}{lccc}
\hline Composite & Number of catalysts & \\
\hline NP1 & $\mathrm{LE}^{b}, \%$ & $\mathrm{LC}^{c}, \%$ \\
NP2 & 30 & 10.0 & 3.1 \\
NP3 & 59 & 9.8 & 6.0 \\
NP4 & 94 & 9.4 & 9.2 \\
NP5 & 169 & 8.4 & 15.4 \\
& 312 & 6.3 & 25.2
\end{tabular}

${ }^{a}$ The numbers represent the average amount of incorporated $\mathrm{FeFe}-$ $\mathrm{COOH}$ per apo-HSF. ${ }^{b}$ The LEs of $\mathrm{FeFe}-\mathrm{COOH}$ nanoparticles were calculated as the weight ratio of incorporated $\mathrm{FeFe}-\mathrm{COOH}$ to fed $\mathrm{FeFe}-\mathrm{COOH} .{ }^{c}$ The LCs of $\mathrm{FeFe}-\mathrm{COOH}$ nanoparticles were calculated as the weight ratio of incorporated FeFe-COOH to FeFe NP. Apo-HSF has a molecular weight of approx. $450 \mathrm{kDa}$.
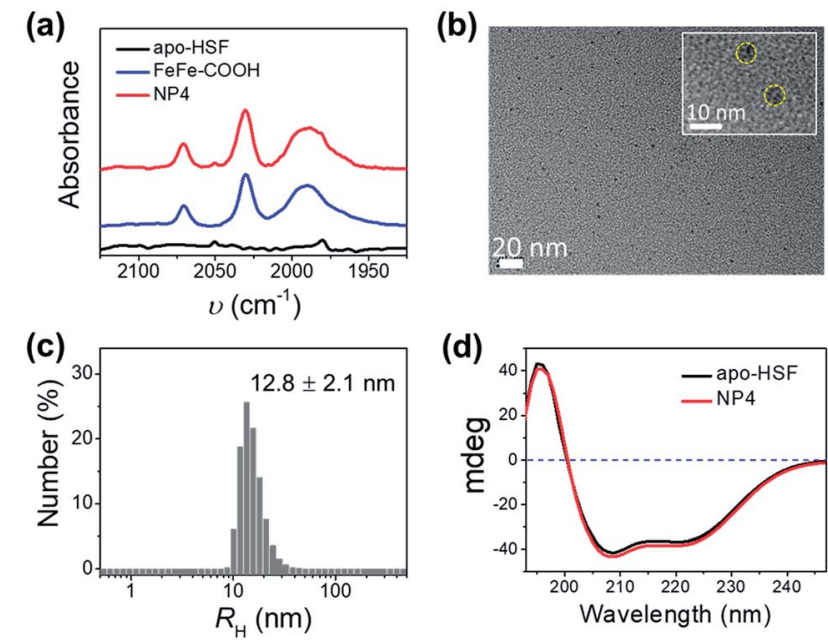

Fig. 2 Characterization of NP4. (a) FT-IR spectra of apo-HSF, FeFe$\mathrm{COOH}$ and NP4. (b) TEM image of non-stained NP4. Inset: HR-TEM of non-stained NP4. The yellow circle indicated the existence of a metal core. (c) DLS analysis of NP4. (d) CD spectra of apo-HSF and NP4 in PBS buffer. 
confirming that the structure of $\mathrm{FeFe}-\mathrm{COOH}$ was well preserved after encapsulation. ${ }^{12}$ Importantly, non-stained NPs were clearly visualized as uniform puncta under a high resolution transmission electron microscope (HR-TEM) (Fig. 2b), indicative of the iron-enriched core. The average diameter was estimated to be $\sim 8 \mathrm{~nm}$, well matching the size of the inner cavity of apo-HSF, which suggests that the metal complexes were mainly located inside the protein cage. Despite the big number of entrapped metal complexes, the average hydrodynamic diameter $\left(R_{\mathrm{H}}\right)$ was comparable to that of free apo-HSF $(12.8 \pm 2.1 \mathrm{~nm}$ versus $11.0 \pm$ $0.8 \mathrm{~nm}$ ) as determined by dynamic light scattering (DLS) (Fig. $2 \mathrm{c}$ and S3 $\dagger$ ). The secondary protein structures, in particular the $\alpha$ helices, were unaffected as evidenced by the constant peaks positively at $195 \mathrm{~nm}$ and negatively at $208 / 222 \mathrm{~nm}$ in the circular dichroism (CD) spectra which were measured before and after the encapsulation process (Fig. 2d) ${ }^{23,35}$ Meanwhile, the change of zeta-potential between apo-HSF and NP4 was negligible $(-18.0 \mathrm{mV}$ versus $-17.5 \mathrm{mV})$. As compared to $\mathrm{FeFe}-\mathrm{COOH}$ that seriously precipitated from aqueous solution at $51 \mu \mathrm{M}$ due to the limited water solubility, NP4 was in a molecularly dispersed state in the aqueous solution as evidenced by the undetectable changes in UV-vis absorption, $R_{\mathrm{H}}$ and CD spectra after one week of storage at $4{ }^{\circ} \mathrm{C}$ (Fig. S4 and S5†). These data were in good agreement with the notion that the NPs have an intact coreshell structure, with large numbers of $\mathrm{FeFe}-\mathrm{COOH}$ encaged in the cavity. The loading capacity (LC) of NP4 was close to that of the protein/FeFe- $\mathrm{COOH}$ composite obtained by the common $\mathrm{pH}$ alteration method (337 versus $367 \mathrm{Fe}$ atoms per single protein) at the same feed ratio $(2000: 1)$, which suggests that most $\mathrm{FeFe}-\mathrm{COOH}$ moieties were accumulated in the inner surface.

The occurrence of binding events associated with multiple coordination sites can be very complicated, as inferred from a quantity of previous reports on X-ray structural analysis of Fe ion-bound apoferritin. ${ }^{36-38}$ By raising the feed ratio to $5000: 1$ (NP5), we found that the loading capacity for $\mathrm{FeFe}-\mathrm{COOH}$ was increased to 312 moieties (equivalent to $624 \mathrm{Fe}$ atoms). This is an extremely large number for apo-HSF to accommodate an organometallic complex, with a loading rate as high as $25 \mathrm{wt} \%$ (Table 1). Assuming the protein cavity has a radius $(R)$ of $4 \mathrm{~nm}$ and the crystal density $(\rho)$ of $\mathrm{FeFe}-\mathrm{COOH}$ is similar to $\left[\left(\mu-\mathrm{SCH}_{2} \mathrm{CH}_{2} \mathrm{CH}_{2} \mathrm{~S}\right)\right.$ $\left.\mathrm{Fe}_{2}(\mathrm{CO})_{6}\right]$ reported to be $1.887 \mathrm{~g} \mathrm{~cm}^{-3},{ }^{39}$ the theoretical capacity $(n)$ was roughly calculated according to eqn (1):

$$
n=\frac{V}{V_{0}}=\left(\frac{4 \pi R^{3} / 3}{M / \rho N_{\mathrm{A}}}\right)
$$

where $V$ is the volume of a single apo-HSF protein molecule, $V_{0}$ is the volume of a single FeFe- $\mathrm{COOH}$ molecule, $N_{\mathrm{A}}$ is the Avogadro constant and $M$ is the molecular weight of $\mathrm{FeFe}-\mathrm{COOH}$. The $n$ was estimated to be 626 , greater than the maximum experimental loading number $(312 \mathrm{FeFe}-\mathrm{COOH}$ moieties in NP5). Hence, we speculated that at a lower level of FeFe- $\mathrm{COOH}$ loading, the $\mathrm{FeFe}-\mathrm{COOH}$ moieties are attached to the inner surface of apoferritin; however, as the accommodation of FeFe$\mathrm{COOH}$ approaches the theoretical saturation point, there are not sufficient binding sites available and thus intermolecular interaction between $\mathrm{FeFe}-\mathrm{COOH}$ moieties may occur.
The mode of binding interactions between $\mathrm{Fe}^{2+}$ ions and apoferritin has been extensively studied, whereas the binding of metal complexes into apoferritin cages remains unclear. Obviously, the limited space of 3 -fold pores and availability of cysteine residues potentially binding the diiron complex could not well interpret the large amount of complex incorporated. We hypothesized that the organic solvent treatment during preparation of NPs and the inner surface properties of apo-HSF that afford plenty of binding sites are crucial for transportation and accumulation of the diiron dithiolate complex.

We compared the loading number of $\mathrm{FeFe}-\mathrm{COOH}$ at a fixed feed ratio of $2000: 1$ under different conditions: (1) NP4-1 was prepared in the absence of acetonitrile in both encapsulation and dialysis processes; (2) NP4 was prepared in PBS and dialysed in the presence of $10 \%$ acetonitrile-PBS, and (3) $10 \%$ acetonitrile was applied in both loading and dialysis processes for NP4-2 formulation. As a result (Table S2 and Fig. S6†), a maximum loading up to 203 catalyst moieties was achieved with NP4-2, in contrast to the notably reduced loading number (81 catalyst moieties) with NP4-1. The organic solvent treatment allows more catalyst molecules to transport into the inner cavity.

The inner wall of apoferritin is known to be highly negatively charged due to the abundant anionic amino acid residues such as glutamic acid. ${ }^{40,41}$ To mimic the anionic environment for assessing the binding affinity, we synthesized a water soluble peptide, poly(L-glutamic acid) ${ }^{42}$ (L-PGA) comprising 52 repeat units, by the ring-opening polymerization method (Fig. 3 and $\mathrm{S} 77^{\dagger}$ ), and found that L-PGA complexed with $\mathrm{FeFe}-\mathrm{COOH}$ to form nanoparticles using the same encapsulation and dialysis protocols for NP4 preparation, as revealed by DLS and TEM analysis (Fig. S8 $\dagger$ ). The condensed nanostructure suggests the strong interaction between $\mathrm{FeFe}-\mathrm{COOH}$ and L-PGA. As a result, the LE and LC of $\mathrm{FeFe}-\mathrm{COOH}$ were estimated to be $19 \%$ and $29 \%$, respectively, comparable to the binding of $\mathrm{FeFe}-\mathrm{COOH}$ by apo-HSF. These data corroborate the assumption that the highly anionic environment is in favour of immobilizing FeFe- $\mathrm{COOH}$, thanks to the coordination between the anionic peptide and diiron part.

To check the interaction between the incorporated FeFe$\mathrm{COOH}$ and photosensitizer (PS) $\mathrm{Ru}(\mathrm{bpy}){ }_{3}{ }^{2+}$, we investigated the luminescence quenching of $\mathrm{Ru}(\mathrm{bpy})_{3}{ }^{2+}$ at $629 \mathrm{~nm}$ by titrating $\mathrm{NP} 4$ into $5.0 \mu \mathrm{M} \mathrm{Ru}(\mathrm{bpy})_{3}{ }^{2+}$ aqueous solution containing $0.1 \mathrm{M}$ sodium ascorbate (NaHA) at $\mathrm{pH} 7.4$, and achieved a SternVolmer quenching constant $\left(K_{\mathrm{SV}}\right)$ of $5.2 \times 10^{3} \mathrm{M}^{-1}$ according to the linear concentration-dependent quenching relationship (Fig. 4a), where $I_{0}$ and $I_{\mathrm{p}}$ denote the $\mathrm{Ru}(\mathrm{bpy})_{3}{ }^{2+}$ luminescence intensity in the absence and presence of incorporated $\mathrm{FeFe}-$ $\mathrm{COOH}$ at concentration $C_{\text {incorporated FeFe-COOH }}$, respectively. This

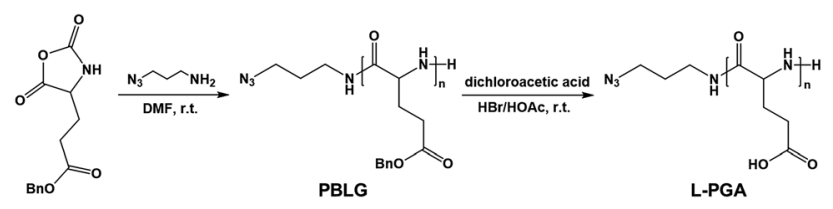

Fig. 3 Synthetic route for L-PGA. 


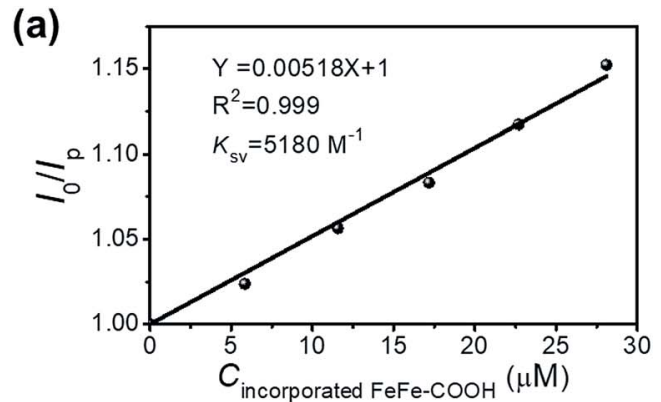

(b)

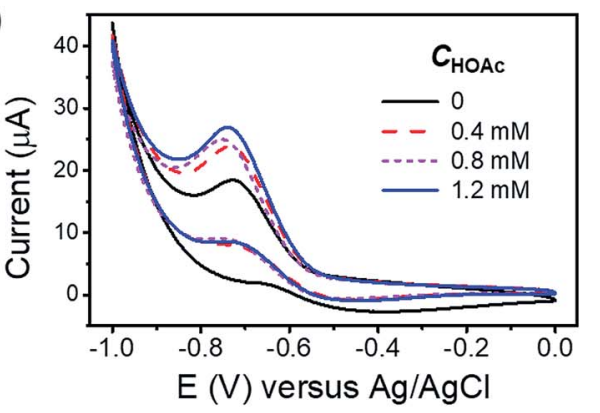

(c)

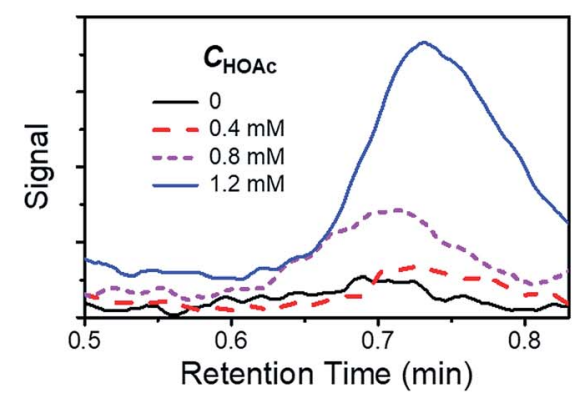

Fig. 4 (a) The Stern-Volmer plot of $I_{0} / I_{\mathrm{p}}$ against $C_{\text {incorporated FeFe-COOH }}$ by successive addition of NP4 to a solution of $\mathrm{Ru}(\mathrm{bpy})_{3}{ }^{2+}(5 \mu \mathrm{M})$. $\mathrm{Ru}(\mathrm{bpy})_{3}{ }^{2+}$ was excited at $453 \mathrm{~nm}$ and luminesced at $629 \mathrm{~nm}$. (b) Cyclic voltammograms of NP4 at $51 \mu \mathrm{M}$ incorporated FeFe- $\mathrm{COOH}$ in the presence of different concentrations of HOAc $(0-1.2 \mathrm{mM})$ in $0.1 \mathrm{M}$ $\mathrm{Na}_{2} \mathrm{SO}_{4}$ solution. (c) $\mathrm{GC}$ spectra of the gas phase collected during electrochemical reaction of NP4, with $\mathrm{H}_{2}$ detected at $\sim 0.7$ min.

$K_{\mathrm{SV}}$ value was very close to that with the quenching of $\mathrm{Ru}(\mathrm{bpy})_{3}{ }^{2+}$ luminescence by free FeFe-COOH $\left(K_{\mathrm{SV}} 5.5 \times 10^{3} \mathrm{M}^{-1}\right)$ under the same conditions, which suggests that efficient electron transfer can take place between the incorporated $\mathrm{FeFe}-\mathrm{COOH}$ and $\mathrm{Ru}(\mathrm{bpy})_{3}{ }^{2+}$. According to a previous report on encapsulating ruthenium bipyridine complexes with apo-HSF, nonspecific embedding of $\mathrm{Ru}(\mathrm{bpy})_{3}{ }^{2+}$ at the protein surface and penetration of $\mathrm{Ru}(\mathrm{bpy})_{3}{ }^{2+}$ into the protein cavity were negligible, ${ }^{26}$ thus minimizing the possibility of PS contact with the caged FeFe$\mathrm{COOH}$. The approaching and accumulation of $\mathrm{Ru}(\mathrm{bpy})_{3}{ }^{2+}$ to the protein surface is driven by the electrostatic attraction as apoHSF has a very negative zeta potential, ${ }^{43}$ which is in favor of efficient electron transfer processes. ${ }^{44}$ This observation was similar to the long range electron transfer between $\mathrm{Ru}(\mathrm{bpy})_{3}{ }^{2+}$ and the catalyst in amphiphilic polymeric micelles reported by Wu's group. ${ }^{9}$ In contrast, with a small $K_{\mathrm{SV}}$ estimated to be 48 $\mathrm{M}^{-1}$, ascorbic acid $\left(\mathrm{H}_{2} \mathrm{~A}\right)$ mediated quenching of $\mathrm{Ru}(\mathrm{bpy})_{3}{ }^{2+}$ luminescence to a much lesser extent (Fig. S9†), ensuring that the excited state of PS was unaffected by $\mathrm{H}_{2} \mathrm{~A}$.
To evaluate the proton reduction capability of $\mathrm{FeFe}-\mathrm{COOH}$ and NPs in the presence of acetic acid (HOAc), we carried out cyclic voltammetry (CV) measurements in $\mathrm{N}_{2}$-saturated solution. The reduction peak was observed at $-0.7 \mathrm{~V}$ versus $\mathrm{Ag} / \mathrm{AgCl}$ to indicate the existence of $\mathrm{Fe}^{\mathrm{I}} \mathrm{Fe}^{0}$ species after one electron transfer $^{45}$ and intensified upon gradual addition of HOAc (Fig. S10a $\dagger$ ), in accordance with an electrochemical catalytic proton reduction process. ${ }^{\mathbf{4 6 7}}$ As compared to the free $\mathrm{FeFe}-$ $\mathrm{COOH}$, the incorporated $\mathrm{FeFe}-\mathrm{COOH}$ indicates a similar electrochemical response by transferring accepted electrons from the electrode to protons for $\mathrm{H}_{2}$ production (Fig. 4b). To verify the produced $\mathrm{H}_{2}$ in the electrochemical reaction, a fixed volume $(1 \mathrm{~mL})$ of gas above the reaction solution containing different concentrations of HOAc was extracted and subjected to gas chromatography (GC). As shown in Fig. 4c, in the GC spectra, $\mathrm{H}_{2}$ was detected at a retention time of $\sim 0.7 \mathrm{~min}$ with increasing signal as the HOAc concentration increased in the $0-1.2 \mathrm{mM}$ range, which reveals that the incorporated $\mathrm{FeFe}-\mathrm{COOH}$ perfectly retained its $\mathrm{FeFe}-\mathrm{H}_{2}$ ase activity in proteins similar to the free $\mathrm{FeFe}-\mathrm{COOH}$ (Fig. S10b $\dagger$ ).

To investigate the photocatalytic behavior of NPs in aqueous solution, we used $\mathrm{Ru}(\mathrm{bpy})_{3}{ }^{2+}$ as $\mathrm{PS}$ and $\mathrm{H}_{2} \mathrm{~A}$ as the proton source and the sacrificial electron donor. In the presence of Ru(bpy $)_{3}{ }^{2+}$

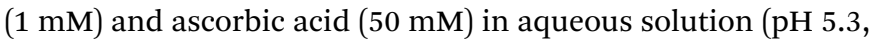
$20 \mathrm{~mL}$ ), NP4 (containing $51 \mu \mathrm{M}$ incorporated FeFe-COOH) was irradiated by a $300 \mathrm{~W}$ xenon $\operatorname{lamp}\left(\lambda>400 \mathrm{~nm}, 200 \mathrm{~mW} \mathrm{~cm}{ }^{-2}\right)$ under vacuum and the evolved $\mathrm{H}_{2}$ was detected by GC. A total amount of $695 \mu \mathrm{L}$ (or $31 \mu \mathrm{mol}$ ) of $\mathrm{H}_{2}$ in $3 \mathrm{~h}$ was collected, resulting in a turnover number (TON) of 31 and $5.2 \times 10^{3}$ on the basis of $\mathrm{FeFe}-\mathrm{COOH}$ moieties and single protein particles, respectively (Fig. 5a). In contrast, irradiation of free $\mathrm{FeFe}-\mathrm{COOH}$ $(51 \mu \mathrm{M})$ led to a low TON of 3.6 under the same conditions in the presence of $\mathrm{Ru}(\mathrm{bpy})_{3}{ }^{2+}$ and ascorbic acid, which means protein encapsulation amplified $\mathrm{H}_{2}$ generation capability by a factor of 8.5. This amplification effect was comparable to that of most of the reported inorganic nano-platforms and assembled vesicles (Table $\mathrm{S} 1 \dagger$ ). The reduced $\mathrm{H}_{2}$ evolution for $\mathrm{FeFe}-\mathrm{COOH}$ lacking protein encapsulation was partially attributed to the limited solubility in acidic solutions which induced formation of catalyst precipitates. We tested the photochemical $\mathrm{H}_{2}$ evolution performance of $\mathrm{FeFe}-\mathrm{COOH}(51 \mu \mathrm{M})$ in acetonitrile/water $(1: 1$, $\mathrm{v} / \mathrm{v}$ ) which well dissolved the catalyst, and found that the volume of evolved $\mathrm{H}_{2}$ only slightly increased (Fig. S11 $\dagger$ ). Although organic solvent prohibited the catalyst from precipitation, it was
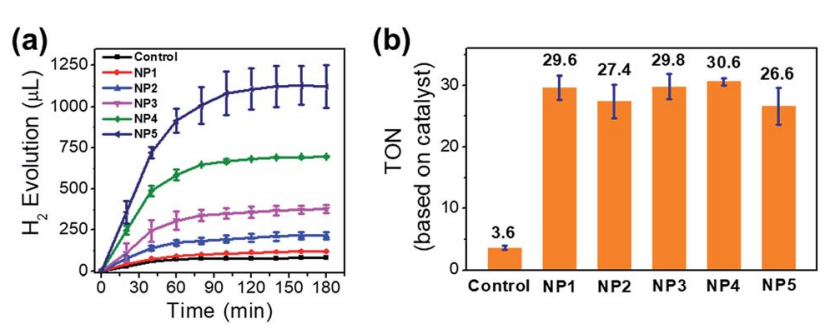

Fig. 5 (a) Photocatalytic $\mathrm{H}_{2}$ evolution and (b) TON based on FeFe$\mathrm{COOH}$ moieties for NP1-NP5, with free FeFe-COOH as a control. The concentration of incorporated FeFe- $\mathrm{COOH}$ was 9.0, 17.7, 28.2, 50.7 and $93.6 \mu \mathrm{M}$, respectively. The optical power was $200 \mathrm{~mW} \mathrm{~cm}^{-2}$. 
unfavorable in proton donating and did not substantially improve $\mathrm{H}_{2}$ production. ${ }^{9}$ No $\mathrm{H}_{2}$ evolution was detected without light or by light irradiation of $\mathrm{FeFe}-\mathrm{COOH}, \mathrm{Ru}(\mathrm{bpy})_{3}{ }^{2+}$, and ascorbic acid separately (Fig. S12 $\dagger$ ), which are controls, confirming that each component is essential for photocatalytic $\mathrm{H}_{2}$ generation.

Factors, such as $\mathrm{pH}$, PS concentration and catalyst feed ratio, have profound effects on the photocatalytic performance. With $\mathrm{NP} 3$ as an example, as the $\mathrm{pH}$ increased from 5.3 to 7.4, the evolved $\mathrm{H}_{2}$ volume in $3 \mathrm{~h}$ was decreased by $59 \%$, owing to the lowered proton concentration that reduced the proton reduction rate (Fig. S13†). The $\mathrm{pH}$-dependence also reflects that no barriers exist for proton transportation in the protein scaffold even though $\mathrm{FeFe}-\mathrm{COOH}$ was caged inside. NP3 was stable at $\mathrm{pH}$ 5.3, as illustrated by the unchanged CD spectra in comparison to apo-HSF (Fig. S14 $\dagger$ ). In consideration of the isoelectric point of apoferritin, more acidic $\mathrm{pH}$ was not applied to avoid protein precipitation. ${ }^{48}$ As shown in Fig. S15, $\dagger$ lowering the $\mathrm{Ru}(\mathrm{bpy})_{3}{ }^{2+}$ concentration from $1.0 \mathrm{mM}$ to $0.2 \mathrm{mM}$ gave rise to a decrease of the total amount of the evolved $\mathrm{H}_{2}$ in $3 \mathrm{~h}$ by $74 \%$, due to the attenuated electron transfer from the excited state of $\mathrm{Ru}(\mathrm{bpy})_{3}{ }^{2+}$ to the caged $\mathrm{FeFe}-\mathrm{COOH}$. Therefore, preferentially we performed photochemical reactions at $\mathrm{pH} 5.3$ using $1 \mathrm{mM} \mathrm{Ru}(\mathrm{bpy})_{3}{ }^{2+}$ for maximization of $\mathrm{H}_{2}$ productivity.

Increase of feed ratio in a range of $300: 1$ to $2000: 1$ (from NP1 to NP4) resulted in greater numbers (30 to 169) of incorporated catalysts per single protein (Table 1), while the LE decreased slightly from 10.0 to $8.4 \%$. Interestingly, despite the higher feed ratio and more evolved $\mathrm{H}_{2}$ (Fig. $5 \mathrm{a}$ and b), the TON values (based on the $\mathrm{FeFe}-\mathrm{COOH}$ moiety) upon $3 \mathrm{~h}$ of irradiation remained almost unchanged. This finding shows that the increase of local catalyst concentration had little impact on the activity of the incorporated catalyst. Interestingly, the catalyst incorporated in proteins showed enhanced activity, although it is separated from the PS situated at the outer protein surface by a 20-25 A-thick protein shell. This means the electron transfer process was efficient over a long distance and did not need very close proximity between the catalyst and PS. Such a photoinduced long-distance electron transfer was not favored by a distance-limited superexchange mechanism, but was probably governed by a multistep electron tunneling pathway which is not rare in metalloproteins. ${ }^{\mathbf{4 9 , 5 0}}$ For example, Knez et al. reported the bi-directional electron transport activity of $\mathrm{L}$-chains across the shell of apo-HSF, ${ }^{51}$ supporting the possible mechanism of electron tunneling which was also suggested by Watt and coworkers in the study of long-distance electron transfer through the 20-25 A shell of apo-HSF. ${ }^{49}$ This process was probably associated with redox active aromatic acids in the L-chains of apo-HSF which possesses 90-95\% L-chains. Each L-chain contains 24 Phe, 6 Tyr and 1 Trp residues with redox potentials of $\sim 1 \mathrm{~V}$ versus NHE or more, and these relay amino acids were reported to act as stepping stones for the nearest neighbour hopping. ${ }^{52-54}$ In addition, $\alpha$-helix is dominant in apo-HSF and the amino bonds along the $\alpha$-helical backbones were electron hopping sites to allow for efficient long-distance electron transfer across the $\alpha$-helix. ${ }^{55}$ The high-hierarchy and well-aligned structure of proteins and peptides enable broad electrical applications. ${ }^{56}$
Compared to the excited $\mathrm{Ru}(\mathrm{bpy})_{3}{ }^{2+}$ with a higher redox potential $\left(\mathrm{E}^{2+*} \beta^{3+}-0.83\right.$ versus $\left.\mathrm{SCE}\right),{ }^{57}$ the incorporated catalyst had a relatively low potential ( $E_{\text {red }} \sim-0.7 \mathrm{~V}$ versus $\mathrm{SCE}$ ), which is suitable for redox reactions. Besides, negatively charged apo-HSF facilitates accumulation of PS cations to its outer surface through electrostatic interaction and the enhanced local concentration of PS ensures sufficient availability of PS to interact with the incorporated catalyst. Hence, on the basis of the above information, we speculated that the core-shell structure of apo-HSF, not simply improving the solubility of the catalyst by a spacious cavity, should account for the enhancement of catalyst activity by facilitating longdistance electron hopping that traversed the protein shell.

After one week of storage of NP4 at $4{ }^{\circ} \mathrm{C}$, in addition to the high stability of the protein structure (Fig. S5 $\dagger$ ), the activity of photocatalytic $\mathrm{H}_{2}$ evolution was perfectly preserved as compared to that of the freshly prepared sample (Fig. S16†). This observation suggests that the state of incorporated FeFe-COOH moieties was not changed as a result of stable immobilization.

The protein caging $312 \mathrm{FeFe}-\mathrm{COOH}$ moieties for NP5, although fewer than the theoretical 626, could be approx. solid. This huge number must exceed the quantity of iron anchoring sites. Under the same photocatalytic conditions, $3 \mathrm{~h}$ light illumination on $0.3 \mu \mathrm{M}$ metalloprotein resulted in $1123 \mu \mathrm{L}$ of evolved $\mathrm{H}_{2}$. The slightly decreased TON (26.6, based on the FeFe-COOH moiety) may reflect the influence on the catalytic activity from the changes of the microenvironment where the catalysts reside. Nevertheless, the TON based on a single protein reaches $8.3 \times 10^{3}$. In general, the single protein affords more $\mathrm{H}_{2}$ as more catalysts are caged.

It is noteworthy that the photochemical $\mathrm{H}_{2}$ evolution ceased after $\sim 100$ min of light irradiation (Fig. 5a). According to the unaffected size and secondary structure as indicated by the DLS and CD spectra (Fig. S17†), the integrity of the protein shell was undisturbed before and after the photochemical reaction. To make sure whether the catalyst or PS led to reaction interruption, we added fresh NP4 or $\mathrm{Ru}(\mathrm{bpy})_{3}{ }^{2+}$ to the reaction mixture after $3 \mathrm{~h}$ light irradiation and continued another run of photochemical reaction that was monitored by GC. As shown in Fig. $6 \mathrm{a}, \mathrm{H}_{2}$ generation was undetectable with re-addition of $\mathrm{Ru}(\mathrm{bpy})_{3}{ }^{2+}$, but resumed for another $100 \mathrm{~min}$ by re-addition of NP4. The experiment was repeated under the same conditions except for the replacement of NP4 with $\mathrm{FeFe}-\mathrm{COOH}$, and similar phenomena were observed (Fig. S18 $\dagger$ ). These results demonstrate that although the PS could last a long-term reaction, the catalyst was deactivated in a protein-independent manner as the reaction proceeded.

We reasoned that decomposition of the catalyst may take place during the photochemical reaction as diiron dithiolatetype clusters were previously reported with the photostability issue. ${ }^{58,59}$ The FT-IR experiment results (Fig. 6b and S19†) showed that the absorption intensity of characteristic $v_{\mathrm{CO}}$ bands for NP4 or FeFe-COOH samples at 1990, 2031, and $2071 \mathrm{~cm}^{-1}$ was gradually attenuated during $0-3 \mathrm{~h}$ of normal photochemical reaction. This evidence confirmed that the photoinduced dissociation of $\mathrm{Fe}-\mathrm{CO}$ bonds occurred and thus affected the photocatalytic performance. The absence or presence of PS had little impact on the photostability of the catalyst (Fig. S20†). 
(a)

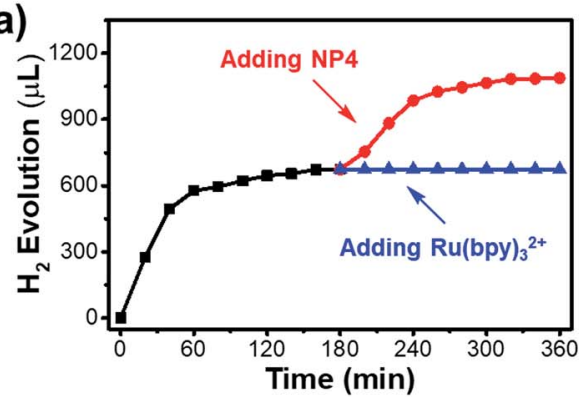

(b)

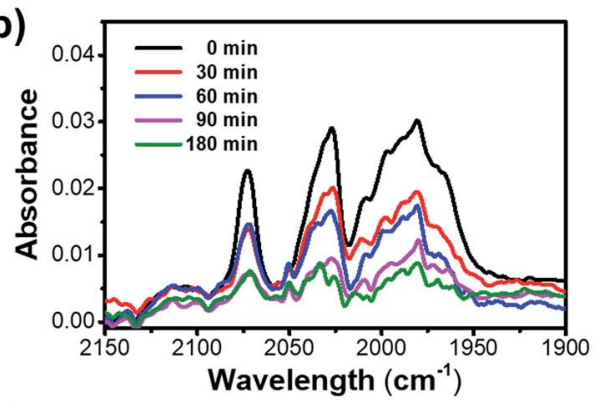

(c)

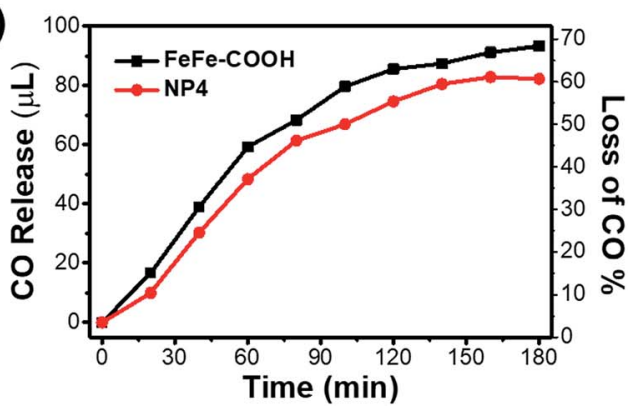

Fig. 6 (a) Photocatalytic $\mathrm{H}_{2}$ evolution from solution ( $\mathrm{pH}$ 5.3) containing $\mathrm{Ru}(\mathrm{bpy})_{3}{ }^{2+}(1 \mathrm{mM})$, ascorbic acid $(50 \mathrm{mM})$ and NP4 $(51 \mu \mathrm{M}$ incorporated FeFe-COOH). The optical power was $200 \mathrm{~mW} \mathrm{~cm}^{-2}$. Reaction was re-performed $3 \mathrm{~h}$ after adding another portion of $\mathrm{Ru}(\mathrm{bpy})_{3}{ }^{2+}(1 \mathrm{mM})$ or NP4 (51 $\mu \mathrm{M}$ incorporated FeFe-COOH). (b) FT-IR spectroscopy of NP4 after different times of photochemical reaction under the same conditions described in (a). (c) The volumes of released $\mathrm{CO}$ and percentages of the loss of $\mathrm{CO}$ ligands after different times of photochemical reaction under the same conditions described in (a) and FeFe- $\mathrm{COOH}(51 \mu \mathrm{M})$ was used for comparison. $\mathrm{CO}$ was detected using an FID detector in GC analysis.

To look close into the decomposition process of NP4 and $\mathrm{FeFe}-\mathrm{COOH}$, we employed a GC technique to quantitatively detect gaseous $\mathrm{CO}$ released from the reaction mixture. The release of $\mathrm{CO}$ in the presence of PS was relatively rapid in the first $100 \mathrm{~min}$ before a slowdown (Fig. 6c). Specifically, approx. $50 \%$ of the CO ligands of the incorporated catalyst in NP4 were dissociated after 100 min of light irradiation, at which point $\mathrm{H}_{2}$ evolution came to a complete cease. This result may suggest full deactivation of the catalyst after three Fe-bonding CO bonds were liberated. The loss of more CO ligands was rather slow, and reached only approx. $60 \%$ as the reaction extended to $3 \mathrm{~h}$. In line with the FT-IR data, the PS and protein showed limited effect on the CO release rate (Fig. S21†), reflecting the irreversible photoinduced catalyst degradation, although the absorption of visible light by the catalyst was weak.

\section{Conclusions}

In summary, the incorporation of a synthetic iron-sulfur cluster, as a model photocatalyst, in apoferritin at neutral $\mathrm{pH}$ led to uniform nanoassemblies with a loading rate as high as $25 \mathrm{wt} \%$. The intact protein nanocage structure with an outer diameter of $\sim 12 \mathrm{~nm}$ was well preserved. Under homogeneous acidic conditions, the photocatalysts in cages exhibited FeFehydrogenase activity to generate $\mathrm{H}_{2}$ with an enhancement of the TON up to 8.5-fold relative to the non-incorporated form upon visible light illumination. The enhanced activity of the incorporated catalyst was associated with the core-shell-shaped protein structure that improved the water solubility of the catalyst and facilitated long-distance electron transportation from photosensitizers to the catalyst across the protein shell. The strong iron binding affinity and tremendous iron loading capacity that have not been found in other protein cages, related to the anionic inner wall of the protein, make apoferritin an ideal scaffold for stable photocatalyst immobilization without compromising catalyst activity. The investigation on the photostability of the diiron dithiolate complex, arising from the metal-carbonyl ligand, will spur development of new catalysts with high activity for long-term photocatalysis.

\section{Conflicts of interest}

There are no conflicts to declare.

\section{Acknowledgements}

We're grateful to Prof. Wei Wang (Nanjing University) for help with DLS and zeta potential measurements, Prof. Dechen Jiang (Nanjing University) for help with CV measurements, and Prof. Weiyin Sun (Nanjing University) for help with GC measurements. We thank the National Basic Research Program of China (2015CB856300), the National Natural Science Foundation of China (21601119), the 1000 Young Talents Program, the Program for Changjiang Scholars and Innovative Research Team in University (IRT1252), Interdisciplinary Training for Graduate Students of Nanjing University (2016CL11), the Innovative Training Program for Undergraduate Students of Nanjing University (G201810284150), and the Fundamental Research Funds for the Central Universities (020514380140) for financial support.

\section{Notes and references}

1 M. Frey, ChemBioChem, 2002, 3, 153.

2 M. B. Wilker, K. E. Shinopoulos, K. A. Brown, D. W. Mulder, P. W. King and G. Dukovic, J. Am. Chem. Soc., 2014, 136, 4316.

3 L. M. Utschig, S. R. Soltau and D. M. Tiede, Curr. Opin. Chem. Biol., 2015, 25, 1.

4 Y. Shim, R. M. Young, A. P. Douvalis, S. M. Dyar, B. D. Yuhas, T. Bakas, M. R. Wasielewski and M. G. Kanatzidis, J. Am. Chem. Soc., 2014, 136, 13371.

5 T. Ueno, H. Tabe and Y. Tanaka, Chem.-Asian J., 2013, 8, 1646. 
6 F. Wang, W. J. Liang, J. X. Jian, C. B. Li, B. Chen, C. H. Tung and L. Z. Wu, Angew. Chem., Int. Ed., 2013, 52, 8134.

7 T. Ueno, S. Abe, N. Yokoi and Y. Watanabe, Coord. Chem. Rev., 2007, 251, 2717.

8 Y. Sano, A. Onoda and T. Hayashi, J. Inorg. Biochem., 2012, 108, 159.

9 F. Wang, M. Wen, K. Feng, W. J. Liang, X. B. Li, B. Chen, C. H. Tung and L. Z. Wu, Chem. Commun., 2016, 52, 457.

10 M. Wen, H. L. Wu, J. X. Jian, X. Z. Wang, X. B. Li, B. Chen, C. H. Tung and L. Z. Wu, ChemPhotoChem, 2017, 1, 260.

11 S. Pullen, H. Fei, A. Orthaber, S. M. Cohen and S. Ott, J. Am. Chem. Soc., 2013, 135, 16997.

12 A. Onoda, Y. Kihara, K. Fukumoto, Y. Sano and T. Hayashi, ACS Catal., 2014, 4, 2645.

13 Y. Sano, A. Onoda and T. Hayashi, Chem. Commun., 2011, 47, 8229.

14 P. C. Jordan, D. P. Patterson, K. N. Saboda, E. J. Edwards, H. M. Miettinen, G. Basu, M. C. Thielges and T. Douglas, Nat. Chem., 2016, 8, 179.

15 C. Orain, F. Quentel and F. Gloaguen, ChemSusChem, 2014, 7, 638.

16 X. Li, Y. Zhang, J. Sun, W. Chen, X. Wang, F. Shao, Y. Zhu, F. Feng and Y. Sun, ACS Appl. Mater. Interfaces, 2017, 9, 19519.

17 L. Banci, I. Bertini, K. L. Bren, M. A. Cremonini, H. B. Gray, C. Luchinat and P. Turano, J. Biol. Inorg Chem., 1996, 1, 117.

18 S. Zhang, J. Zang, H. Chen, M. Li, C. Xu and G. Zhao, Small, 2017, 13, 1701045.

19 E. C. Theil, R. K. Behera and T. Tosha, Coord. Chem. Rev., 2013, 257, 579.

20 Z. Zhen, W. Tang, H. Chen, X. Lin, T. Todd, G. Wang, T. Cowger, X. Chen and J. Xie, ACS Nano, 2013, 7, 4830.

21 T. Ueno, M. Abe, K. Hirata, S. Abe, M. Suzuki, N. Shimizu, M. Yamamoto, M. Takata and Y. Watanabe, J. Am. Chem. Soc., 2009, 131, 5094.

22 C. Pozzi, S. Ciambellotti, C. Bernacchioni, F. Di Pisa, S. Mangani and P. Turano, Proc. Natl. Acad. Sci. U. S. A., 2017, 114, 2580.

23 N. Pontillo, G. Ferraro, J. R. Helliwell, A. Amoresano and A. Merlino, ACS Med. Chem. Lett., 2017, 8, 433.

24 K. Fujita, Y. Tanaka, S. Abe and T. Ueno, Angew. Chem., Int. Ed., 2016, 55, 1056.

25 K. Fujita, Y. Tanaka, T. Sho, S. Ozeki, S. Abe, T. Hikage, T. Kuchimaru, S. Kizaka-Kondoh and T. Ueno, J. Am. Chem. Soc., 2014, 136, 16902.

26 X. Li, Y. Zhang, H. Chen, J. Sun and F. Feng, ACS Appl. Mater. Interfaces, 2016, 8, 22756.

27 G. Jutz, P. van Rijn, B. Santos Miranda and A. Böker, Chem. Rev., 2015, 115, 1653.

28 M. Truffi, L. Fiandra, L. Sorrentino, M. Monieri, F. Corsi and S. Mazzucchelli, Pharmacol. Res., 2016, 107, 57.

29 K. Fan, C. Cao, Y. Pan, D. Lu, D. Yang, J. Feng, L. Song, M. Liang and X. Yan, Nat. Nanotechnol., 2012, 7, 459.

30 Z. Wang, H. Gao, Y. Zhang, G. Liu, G. Niu and X. Chen, Front. Chem. Sci. Eng., 2017, 11, 633.

31 B. Maity, K. Fujita and T. Ueno, Curr. Opin. Chem. Biol., 2015, 25, 88 .
32 X. Jiang, L. Long, H. Wang, L. Chen and X. Liu, Dalton Trans., 2014, 43, 9968.

33 D. H. Kim, H. S. Hwang and K. Na, Biomacromolecules, 2018, 19, 3301.

34 X. Wang and Z. Guo, Chem. Soc. Rev., 2013, 42, 202.

35 A. K. Jones, B. R. Lichtenstein, A. Dutta, G. Gordon and P. L. Dutton, J. Am. Chem. Soc., 2007, 129, 14844.

36 L. Toussaint, L. Bertrand, L. Hue, R. R. Crichton and J. P. Declercq, J. Mol. Biol., 2007, 365, 440.

37 R. K. Behera and E. C. Theil, Proc. Natl. Acad. Sci. U. S. A., 2014, 111, 7925.

38 G. R. Bakker and R. F. Boyer, J. Biol. Chem., 1986, 261, 13182. 39 E. J. Lyon, I. P. Georgakaki, J. H. Reibenspies and M. Y. Darensbourg, Angew. Chem., Int. Ed., 1999, 38, 3178.

40 J. S. Jang, S. Yu, S. J. Choi, S. J. Kim, W. T. Koo and I. D. Kim, Small, 2016, 12, 5989.

41 T. Tosha, H. L. Ng, O. Bhattasali, T. Alber and E. C. Theil, J. Am. Chem. Soc., 2010, 132, 14562.

42 Z. Q. Wu, R. J. Ono, Z. Chen, Z. Li and C. W. Bielawski, Polym. Chem., 2011, 2, 300-302.

43 R. Xing, X. Wang, C. Zhang, Y. Zhang, Q. Wang, Z. Yang and Z. Guo, J. Inorg. Biochem., 2009, 103, 1039.

44 K. M. Shin, J. W. Lee, G. G. Wallace and S. J. Kim, Sens. Actuators, B, 2008, 133, 393.

45 J. X. Jian, Q. Liu, Z. J. Li, F. Wang, X. B. Li, C. B. Li, B. Liu, Q. Y. Meng, B. Chen, K. Feng, C. H. Tung and L. Z. Wu, Nat. Commun., 2013, 4, 2695.

46 J. F. Capon, F. Gloaguen, F. Y. Pétillon, P. Schollhammer and J. Talarmin, Coord. Chem. Rev., 2009, 253, 1476.

47 M. L. Singleton, D. J. Crouthers, R. P. Duttweiler III, J. H. Reibenspies and M. Y. Darensbourg, Inorg. Chem., 2011, 50, 5015.

48 L. Balejčíková, V. M. Garamus, M. V. Avdeev, V. I. Petrenko, L. Almásy and P. Kopčanský, Colloids Surf., B, 2017, 156, 375.

49 G. D. Watt, D. Jacobs and R. B. Frankel, Proc. Natl. Acad. Sci. U. S. A., 1988, 85, 7457.

50 C. D. Bostick, S. Mukhopadhyay, I. Pecht, M. Sheves, D. Cahen and D. Lederman, Rep. Prog. Phys., 2018, 81, 026601.

51 U. Carmona, L. Li, L. Zhang and M. Knez, Chem. Commun., 2014, 50, 15358.

52 https://www.uniprot.org.

53 J. G. Nathanael, L. F. Gamon, M. Cordes, P. R. Rable, T. Bally, K. M. Fromm, B. Giese and U. Wille, ChemBioChem, 2018, 19, 922.

54 N. L. Ing, M. Y. El-Naggar and A. I. Hochbaum, J. Phys. Chem. B, 2018, 122, 10403.

55 N. Amdursky, ChemPlusChem, 2015, 80, 1075.

56 S. S. Panda, H. E. Katz and J. D. Tovar, Chem. Soc. Rev., 2018, 47, 3640.

57 Y. Na, P. Wei and L. Zhou, Chem.-Eur. J., 2016, 22, 10365.

58 A. I. Stewart, J. A. Wright, G. M. Greetham, S. Kaziannis, S. Santabarbara, M. Towrie, A. W. Parker, C. J. Pickett and N. T. Hunt, Inorg. Chem., 2010, 49, 9563.

59 I. Silaghi-Dumitrescu, T. E. Bitterwolf and R. B. King, J. Am. Chem. Soc., 2006, 128, 5342. 